\title{
Neurons Specifically Activated by Fear Learning in Lateral Amygdala Display Increased Synaptic Strength
}

\author{
C. W. Butler, ${ }^{1}$ 이. M. Wilson, ${ }^{1}$ J. Oyrer, ${ }^{2}$ T. J. Karle, ${ }^{2}$ S. Petrou, ${ }^{2}$ J. M. Gunnersen, ${ }^{1}$ M. Murphy, ${ }^{1}$ and \\ C. A. Reid ${ }^{2}$
}

DOI:http://dx.doi.org/10.1523/ENEURO.0114-18.2018

${ }^{1}$ Department of Anatomy and Neuroscience, University of Melbourne, Parkville, VIC 3010, Australia and ${ }^{2}$ Florey Institute of Neuroscience and Mental Health, Parkville, VIC 3010, Australia

\begin{abstract}
The lateral amygdala (LA) plays a critical role in the formation of fear-conditioned associative memories. Previous studies have used c-fos regulated expression to identify a spatially restricted population of neurons within the LA that is specifically activated by fear learning. These neurons are likely to be a part of a memory engram, but, to date, functional evidence for this has been lacking. We show that neurons within a spatially restricted region of the LA had an increase in both the frequency and amplitude of spontaneous postsynaptic currents (sPSC) when compared to neurons recorded from home cage control mice. We then more specifically addressed if this increased synaptic activity was limited to learning-activated neurons. Using a fos-tau-LacZ (FTL) transgenic mouse line, we developed a fluorescence-based method of identifying and recording from neurons activated by fear learning $\left(F T L^{+}\right)$in acute brain slices. An increase in frequency and amplitude of sPSCs was observed in $F T L^{+}$ neurons when compared to nonactivated $F L^{-}$neurons in fear-conditioned mice. No learning-induced changes were observed in the action potential (AP) input-output relationships. These findings support the idea that a discrete LA neuron population forms part of a memory engram through changes in synaptic connectivity.
\end{abstract}

Key words: amygdala; cFos; engram; fear learning; plasticity; synapse

\section{Significance Statement}

The lateral amygdala (LA) is critical for the formation of associative fear memories, such as those formed by fear conditioning. A subset of neurons in LA are activated by fear conditioning suggesting that they may be part of a memory engram. However, there is no functional evidence to support this view. Electrophysiological characterization of LA neurons shows that the frequency and amplitude of synaptic events increase following fear conditioning. A method based on $\beta$-galactosidase as a reporter was developed to locate activated neurons in acute slice. An increase in frequency and amplitude of synaptic events was observed in activated compared to nonactivated neurons supporting the idea that a discrete LA neuron population forms part of a memory engram.

\section{Introduction}

Memory formation has long been hypothesized to occur via enhanced synaptic connectivity between populations of neurons in the brain (Hebb, 1949). While there is

Received March 25, 2018; accepted June 3, 2018; First published June 20, 2018.

The authors declare no competing financial interests.

Joint corresponding authorship: C.A.R. and M.M.

Author contributions: C.W.B., M.M., and C.A.R. designed research; C.W.B.,

J.O., and Y.M.W. performed research; C.A.R. and S.P. contributed much indirect evidence supporting this hypothesis (Thompson, 2005; Josselyn et al., 2015; Sweatt, 2016), direct evidence is lacking because of the difficulty in identifying neurons that are specifically involved in the

unpublished reagents/analytic tools; C.W.B., J.O., T.J.K., J.M.G., M.M., and C.A.R. analyzed data; C.W.B., Y.M.W., J.M.G., M.M., and C.A.R. wrote the paper. This work was supported by the National Health and Medical Research Council, Australia, Program Grant 10915693 (to S.P. and C.A.R.). C.A.R. was supported by a Dowd Fellowship. The Florey Institute of Neuroscience and Mental Health is supported by Victorian State Government infrastructure funds. 
formation of a particular memory. One model of learning and memory which has facilitated the identification of neurons involved in memory is classical fear conditioning. Fear conditioning is a well-validated model of associative learning, with the lateral amygdala (LA) strongly implicated in the formation of the associative memories (Maren, 2001; Pape and Stork, 2003; Fanselow and Poulos, 2005; Kim and Jung, 2006; LeDoux, 2007; Johansen et al., 2011). Extracellular single-unit recordings of LA neurons during auditory fear conditioning show that a subpopulation of LA neurons alters their rate of toneevoked firing (Repa et al., 2001). In addition, selective ablation of a subset of CREB-overexpressing neurons in the LA results in the erasure of a conditioned fear memory (Han et al., 2009; Rogerson et al., 2016). These studies suggest that plasticity in only a subset of LA neurons forms part of the memory trace in fear learning.

Immediate early gene expression provides one method of identifying neurons that have been functionally activated during the learning process (Dragunow, 1996). The immediate early gene $c$-fos has been extensively used as a marker of neuronal activation (Knapska et al., 2007) and previous studies have employed $c$-fos regulated expression in the transgenic fos-tau-LacZ (FTL) mouse line to identify functionally activated circuitry in the brain (Murphy et al., 2007; Wilson and Murphy, 2009). Using FTL mice, a number of discrete, anatomically defined populations of neurons in different parts of the brain were identified as being specifically activated by fear learning (Wilson and Murphy 2009; Trogrlic et al., 2011; Butler et al., 2015). In particular, a population of learningactivated $\mathrm{FTL}^{+}$neurons was found within a spatially restricted region of the ventrolateral nucleus of the LA (LAvl). Other studies are also consistent with neurons specifically in LAvl playing a key role in fear memory (Schafe et al., 2000; Bergstrom et al., 2013; Besnard et al., 2014). Thus, where it is established that activation of the ERK1/2 kinase in LA is required for fear memory formation, ERK $1 / 2$ activation following fear conditioning occurs predominantly in neurons in LAvl (Schafe et al., 2000), in a similar pattern to that seen with $\mathrm{FTL}^{+}$neurons.

Given the importance of the LA in the formation of fear memory, the learning-activated $\mathrm{FTL}^{+}$neurons are prime candidates for direct involvement in fear memory. However, it has not been established if these neurons undergo specific changes in their synaptic or intrinsic properties following activation in fear learning. Such studies may provide further evidence both for involvement of these

Acknowledgements: We thank the Biological Optical Microscopy Platform (BOMP) for their assistance.

Correspondence should be addressed to either of the following: Christopher A. Reid, Florey Institute of Neuroscience and Mental Health, The University of Melbourne, Parkville, Victoria 3010, Australia, E-mail: careid@unimelb.edu.au; or Mark Murphy, Department of Anatomy and Neuroscience, The University of Melbourne, Parkville, Victoria 3010, Australia, E-mail: m.murphy@unimelb.edu.au.

DOI:http://dx.doi.org/10.1523/ENEURO.0114-18.2018

Copyright (C) 2018 Butler et al.

This is an open-access article distributed under the terms of the Creative Commons Attribution 4.0 International license, which permits unrestricted use, distribution and reproduction in any medium provided that the original work is properly attributed. neurons in fear memory and for the nature of the "memory engram." In this study, we first trained wild-type mice to simultaneously record the synaptic and firing properties of LAvl neurons after fear learning. Recordings from neurons in brain slices revealed significant increases in the amplitude and frequency of spontaneous synaptic events in a subpopulation of LAvl neurons from fear-conditioned mice compared with neurons from home cage mice. Subsequently, we used the activity-dependent expression of the FTL transgene to target recordings to the learning activated neurons in brain slices from trained FTL mice. Similar increases in amplitude and number of spontaneous synaptic events recorded from $\mathrm{FTL}^{+}$neurons were observed, relative to their nonactivated neighbors. We suggest that these synaptic changes, which occur within a specific population of LAvl neurons following learning, are central to the formation of the fear memory engram.

\section{Materials and Methods}

\section{Animals}

All animal procedures were performed in accordance with the University of Melbourne Animal Care Committee's regulations. Male $\mathrm{FTL}^{-}$and $\mathrm{FTL}^{+}$mice, on a C57BL6/J background, aged four to seven weeks, were housed in standard $15 \times 30 \times 12 \mathrm{~cm}$ cages on a $12 / 12 \mathrm{~h}$ light/dark cycle and had food and water supplied ad libitum. Two days before the commencement of the experiment, mice were singly housed in cages and relocated to a dedicated behavioral laboratory. In this facility, mice were housed under quiet (60 dB), low-light (15-20 Lux) conditions and a 12/12 h light/dark cycle.

\section{Context fear conditioning}

Fear conditioning was conducted using a computerized system (Clever Sys Inc.). The conditioning chamber $(32 \times$ $26 \times 21 \mathrm{~cm}$ ) was contained within a sound-attenuating compartment. The floor of the chamber consisted of stainless steel rods connected to a shocker-scrambler unit capable of delivering electric shocks of defined duration and intensity. The chamber was cleaned with $70 \%$ ethanol between training and testing sessions. For fear conditioning, mice were placed in the chamber for $3 \mathrm{~min}$, after which they received a 1.0-mA, 2-s footshock. The mice then remained in the chamber for a further $30 \mathrm{~s}$ before being returned to their home cages. For the histochemistry experiment, in addition to the previous training conditions, an immediate shock group was exposed to a 1.0-mA, 2-s footshock immediately on entry into the training chamber. Mice in this group then remained in the training chamber for $3 \mathrm{~min}$ and $30 \mathrm{~s}$. The immediately shocked mice did not exhibit any context-associated fear learning when tested. Furthermore, non-learning control mice are not reported to exhibit appreciable FTL expression in the LAvl (Trogrlic et al., 2011).

Mice remained in their home cages for $3 \mathrm{~h}$ after training, to induce $F T L$ expression in activated neurons. Mice were then tested for context-associated fear by placing the mice back in the same training chamber for 3 min. Freezing and moving behavior was recorded, using automated software (Clever Sys Inc.). Mice were anaesthetized im- 
mediately after testing. Home cage mice were anaesthetized immediately on removal from their home cages. In total, $13 \mathrm{FTL}^{-}$(eight home cage, six context fearconditioned) and seven $\mathrm{FTL}^{+}$(all context fearconditioned) were used.

\section{Histochemistry}

$\mathrm{FTL}^{+}$neurons can be identified in fixed tissue using $\beta$-galactosidase histochemistry. To show learninginduced $\mathrm{FTL}^{+}$neurons in the LAvl region, context fearconditioned and immediate shock mice were sacrificed immediately following testing ( $3 \mathrm{~h}$ after training). Brains were removed from the mice and $300-\mu \mathrm{m}$ coronal slices were cut on a vibratome (VT1200; Leica). Slices were immersion fixed in $4 \%$ paraformaldehyde for $10 \mathrm{~min}$ and transferred to separate wells containing $400-\mu l \mathrm{X}$-gal solution (10 mM potassium ferricyanide, $10 \mathrm{mM}$ potassium ferrocyanide, $40 \mathrm{mM} \mathrm{MgCl}$, and $2 \mathrm{mg} / \mathrm{ml}$ 5-bromo-4chloro-3-indolyl- $\beta$-D-galactopyranoside; Roche, Life Sciences) in $0.1 \mathrm{M}$ PBS for $24 \mathrm{~h}$ at room temperature, with agitation. The slices were then rinsed with PBS and mounted onto Superfrost+ glass slides (Thermo Fisher Scientific). Sections were left to dry and coverslipped.

\section{Electrophysiology}

Mice were anaesthetized with $2 \%$ isofluorane, before decapitation. The brains were quickly removed and placed into ice cold cutting solution $(125 \mathrm{mM}$ choline chloride, $2.5 \mathrm{mM} \mathrm{KCl}, 0.4 \mathrm{mM} \mathrm{CaCl}_{2}, 6 \mathrm{mM} \mathrm{MgCl}_{2}, 1.25$ $\mathrm{mM} \mathrm{NaH}{ }_{2} \mathrm{PO}_{4}, 26 \mathrm{mM} \mathrm{NaHCO}_{3}$, and $20 \mathrm{mM}$ D-glucose) saturated with carbogen gas $\left(95 \% \quad \mathrm{O}_{2}-5 \% \mathrm{CO}_{2}\right)$, and $300-\mu \mathrm{m}$ coronal slices were cut on a Vibratome (VT1200; Leica). Slices containing the LA (approximately two slices per mouse) were incubated at room temperature for a minimum of $1 \mathrm{~h}$ in artificial CSF (aCSF; $125 \mathrm{mM} \mathrm{NaCl}, 2.5$ $\mathrm{mM} \mathrm{KCl}, 2 \mathrm{mM} \mathrm{CaCl}$, $2 \mathrm{mM} \mathrm{MgCl}$, $1.25 \mathrm{mM} \mathrm{NaH}_{2} \mathrm{PO}_{4}$, $26 \mathrm{mM} \mathrm{NaHCO}_{3}$, and $10 \mathrm{mM} \mathrm{D}$-glucose) saturated with carbogen. For FTL experiments, $25 \mu \mathrm{M} \mathrm{C}_{12}$-fluoresceindi-( $\beta$-D-galactopyranoside) $\left(\mathrm{C}_{12} \mathrm{FDG}\right.$, Imagene Green, Thermo Fisher Scientific) was added to the aCSF solution.

For patch clamping experiments, slices were transferred to a submerged chamber and perfused $(8 \mathrm{ml} / \mathrm{min})$ with aCSF at room temperature. The LAvl was located, and neurons were visualized with IR-DIC microscopy. Glutamatergic projection neurons were targeted for recording, distinguished from interneurons by large pyramidal-like somata (Sosulina et al., 2006). Electrodes were pulled using a Sutter P-2000 puller (Sutter Instruments) from borosilicate micropipettes (World Precision Instruments) with an initial resistance of around 3-6 $\mathrm{M} \Omega$. Electrodes were filled with: $125 \mathrm{mM} \mathrm{K}$-gluconate, $5 \mathrm{mM}$ $\mathrm{KCl}, 2 \mathrm{mM} \mathrm{MgCl}_{2}$, $10 \mathrm{mM}$ HEPES, $4 \mathrm{mM}$ ATP-Mg, $0.3 \mathrm{mM}$ GTP-Na, $10 \mathrm{mM}$ tris-phosphocreatine, and $10 \mathrm{mM}$ EGTA $(\mathrm{pH} 7.2,290$ OsM). Biocytin $(2 \mathrm{mg} / \mathrm{ml})$ was included to allow morphologic examination and verification of $\mathrm{FTL}^{+}$ neurons post hoc. Whole-cell patch clamp recordings were made using a MultiClamp 700A amplifier and pClamp acquisition software (Molecular Devices) from neurons visually identified using infrared DIC imaging (BX51, Olympus). For FTL experiments, neurons were identified as either $F T L^{+}$or $F T L^{-}$by the presence or absence of $\mathrm{C}_{12} \mathrm{FDG}$ fluorescence using a GFP filter set (excitation 457-487 $\mathrm{nm}$ and emission 502-538 nm). The number of neurons recorded for the experiment involving the application of $\mathrm{C}_{12} \mathrm{FDG}$ was 13 from FTL mice (six $F T L^{-}$, seven $F T L^{+}$; all context fear-conditioned). In a subset of these experiments we were able to record at -50 $\mathrm{mV}$ (four $\mathrm{FTL}^{-}$neurons, six $\mathrm{FTL}^{+}$neurons). For the nontargeted experiment, 61 neurons were recorded from wild-type mice ( 28 from home cage mice, 33 from context fear-conditioned mice). No more than two neurons were recorded from each brain slice.

\section{Firing properties}

Firing properties were recorded in current clamp mode. Bridge balance and capacitance compensation was applied to all recordings. Voltage recordings were filtered at $30 \mathrm{kHz}$ and sampled at $100 \mathrm{kHz}$. Resting membrane potential was measured and neurons recorded as being more than $-55 \mathrm{mV}$ were excluded. A holding current was injected into neurons, if required, setting their holding potential to approximately $-65 \mathrm{mV}$. A current injection/ action potential (AP) frequency relationship was established by injecting 30 current steps of 500 -ms duration (10-pA incremental steps from -30 to $260 \mathrm{pA}$ ). All electrophysiological data were analyzed using AxoGraph $X$ software. To calculate membrane time constant, an exponential function was fit to the voltage trace following a -20-pA current injection for each cell. An automated detection algorithm was used to detect AP with visual confirmation. AP threshold voltage was defined as the voltage at which gradient reached $10 \mathrm{mV} / \mathrm{ms}^{-1}$. For the average AP wave form analysis, APs were aligned to the threshold. AP properties measured were peak height, width at $50 \%$ of height, rise time (10-90\% height), and decay time (100-50\%). Peak AP amplitude was measured from threshold to peak. Rheobase was defined as the current injection that first fired an AP.

\section{Synaptic analysis}

Spontaneous postsynaptic currents (sPSCs) were measured in voltage-clamp mode in the absence of any neurotransmitter blockers. Currents were recorded at -70 and $-50 \mathrm{mV}$ and sampled at $10 \mathrm{kHz}$ with filtering set at $3 \mathrm{kHz}$. sPSCs were identified using event detection in Axograph $X$ (Axograph Scientific Software). The detection threshold of SPSCs was set at four times the SD of the noise. Each automatically identified event was manually confirmed. Amplitude and interevent interval (IEI) were calculated and cumulative probability curves constructed using 60-s gap-free recording with at least 25 events per neuron. No series resistance compensation was applied. NBQX (20 $\mu \mathrm{M})$ and APV $(50 \mu \mathrm{M})$ were added to ACSF to determine the reversal potential of $\mathrm{GABA}_{\mathrm{A}}$ receptor-mediated $\mathrm{Cl}^{-}$ current (measured from seven wild-type neurons). Synaptic events were recorded at various voltages and their amplitudes measured using the automated method described above. We have not accounted for liquid junction potential in any recordings. 

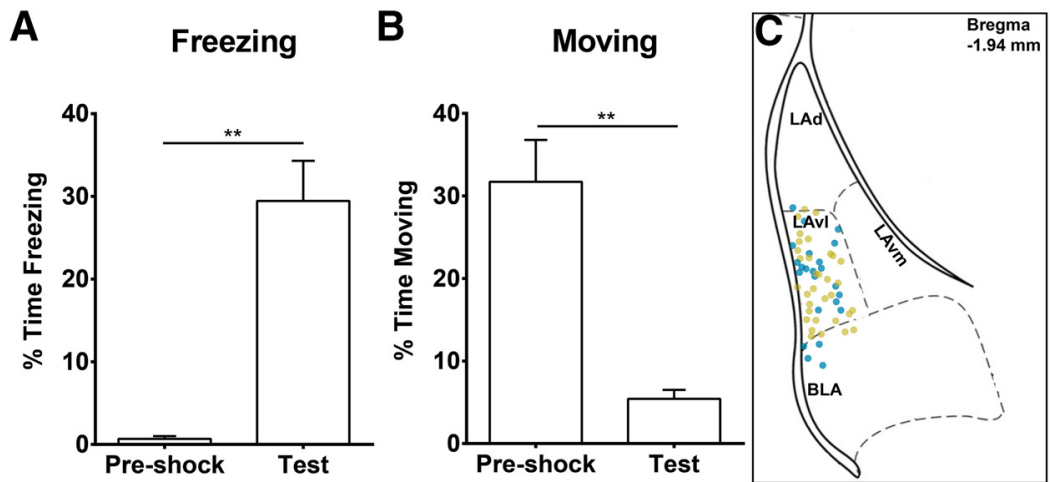

Figure 1. Recorded neurons in the LAvl region from fear-conditioned and home cage mice. fear-conditioned mice were shown to have acquired a context-fear memory by a significant increase in freezing behavior $(p=0.0018 ; \boldsymbol{A})$ and a significant decrease in moving behavior $(p=0.0015, n=6 ; \boldsymbol{B})$. $\boldsymbol{C}$, Cartoon illustrating the position of whole-cell recorded neurons within the LAvl region of the amygdala from fear-conditioned mice and home cage control mice. Blue markers = home cage; yellow markers = fear-conditioned trained mice; $* *$ indicates statistical significant change.

\section{Statistics and Gaussian peak fitting}

All statistical tests were performed with GraphPad software (Prism). Freezing and moving data were analyzed using two-tailed Student's $t$ tests. SPSC IEls and amplitudes were analyzed using Student's $t$ tests with Welch's correction, while cumulative probability curves were compared using the Kolmogorov-Smirnov test. 10 curves were analyzed using two-way ANOVAs, examining current injection and FTL status as sources of variation. AP parameters were compared using unpaired Student's $t$ tests with Welch's correction. A peak fitting algorithm was applied to the data using an unconstrained nonlinear optimization algorithm to decompose the percentage of recorded neurons versus SPSC frequency and amplitude data into Gaussian peaks (only the number of peaks was specified). The peak fits used the MATLAB script of "findpeak.m" (https://terpconnect.umd.edu/ toh/spectrum/ InteractivePeakFitter.htm). Bar graphs presented in the figures represent mean \pm SEM.

\section{Fluorescence immunohistochemistry}

Fluorescence immunohistochemistry was used to verify the FTL status of recorded and biocytin-filled neurons from FTL mice. After patch-clamp experiments, slices were immersion fixed with $4 \%$ paraformaldehyde for $1 \mathrm{~h}$. Slices were incubated with blocking solution (3\% bovine serum albumin, $0.3 \%$ Triton $\mathrm{X}-100$, and $50 \mu \mathrm{M}$ glycine, diluted in PBS) for $1 \mathrm{~h}$ on an orbital shaker, followed by primary antibody solution [chicken anti- $\beta$-galactosidase (Abcam, RRID: AB_307210), diluted 1:1000 in 0.1\% Triton X-100/PBS] overnight. Slices were then exposed to secondary antibody solution (goat anti-chicken Alexa Fluor 488 1:500, Streptavidin 594 1:500, diluted in 0.1\% Triton $\mathrm{X}-100 / \mathrm{PBS})$ for $6 \mathrm{~h}$. Slices were mounted in PBS onto Superfrost + glass slides (Thermo Fisher Scientific), and coverslipped using fluorescent mounting medium (Dako). Slides were visualized using a confocal microscope (LSM5, Carl Zeiss) equipped with a $63 \times$ oil-immersion objective (NA 1.4). FTL expression was detected after illumination via an Argon laser at $488 \mathrm{~nm}$ (emission bandpass filter 515-530 nm). Biocytin fluorescence was excited via a DPSS laser at $561 \mathrm{~nm}$ and the emission collected using a bandpass filter (575-615 nm). Dual channel z-stack images were taken (1024 pixels $\times 1024$ pixels $\times 55$ planes, voxel size $0.12 \times 0.12 \times 0.43 \mu \mathrm{m})$ and then projected using maximum intensity (ImageJ, $\mathrm{NIH})$.

\section{Results}

\section{LAvl neurons display increased spontaneous postsynaptic potential frequency and amplitude following fear conditioning}

To see whether fear learning had any effects on the electrophysiological characteristics of neurons in LA, a group of wild-type mice were fear-conditioned for comparison with a home cage control group. Consistent with having learnt contextual fear, the fear-conditioned mice had significantly increased freezing episodes and reduced movement (Fig. $1 A, B$; pre-shock freezing $M=0.66, S D=$ 0.82 ; test freezing $M=29.5, S D=12 ; t_{(5)}=6, p=0.0018$; pre-shock moving $M=32, S D=13$; test moving $M=5.4$, $\left.S D=2.7 ; t_{(5)}=6.3, p=0.0015\right)$. A small subset of neurons within the LAvl has been previously identified to be specifically activated by fear conditioning (Wilson and Murphy, 2009; Trogrlic et al., 2011; Butler et al., 2015). Whole-cell recordings were made from neurons in this LAvl subnucleus region from fear-conditioned and home cage control mice as marked in Figure $1 C$. There were no differences in the recorded passive neuron properties as reported in Table 1.

We measured sPSCs at a $-70-\mathrm{mV}$ holding potential to evaluate excitatory/inhibitory synaptic network activity onto these neurons (Fig. 2A,B). The cumulative frequency plot of the IEI for sPSCs showed a significant left-shift of the curve for neurons recorded from fear-conditioned mice compared to home cage mice (Fig. 2C; Kolmogorov-Smirnov $\mathrm{D}=0.222, p<0.0001$, averaged data: $\mathrm{HC} M=0.38 \mathrm{~s}$, $S D=0.5 \mathrm{~s} ; \mathrm{FC} M=0.23 \mathrm{~s}, S D=0.38 \mathrm{~s} ; t_{(6239)}=17.1, p<$ 0.0001). Furthermore, the cumulative frequency plot of the sPSC amplitude showed a significant right shift for neurons recorded from fear-conditioned mice compared to home caged mice (Fig. 2D; Kolmogorov-Smirnov $D=0.2159, p<$ 0.0001 , averaged data: $\mathrm{HC} M=10.4 \mathrm{pA}, S D=5.9 \mathrm{pA} ; \mathrm{FC}$ $\left.M=15.3 \mathrm{pA}, S D=11.7 \mathrm{pA} ; t_{(12210)}=30.8, p<0.0001\right)$. 
Table 1. Passive neuron properties

\begin{tabular}{|c|c|c|c|c|c|c|c|c|}
\hline & \multicolumn{4}{|c|}{ Untargeted neurons } & \multicolumn{4}{|c|}{ Targeted neurons } \\
\hline & $\mathrm{HC}$ & $\mathrm{FC}$ & $t$ & $p$ & $F T L^{+}$ & $F T L^{-}$ & $t$ & $p$ \\
\hline Input resistance $(\mathrm{M} \Omega)$ & $273 \pm 139$ & $281 \pm 143$ & 1.1 & 0.25 & $177 \pm 59$ & $162 \pm 86$ & 0.73 & 0.73 \\
\hline Membrane time constant (ms) & $51 \pm 16$ & $56 \pm 16$ & 0.5 & 0.60 & $47 \pm 10$ & $42 \pm 10$ & 1.21 & 0.25 \\
\hline
\end{tabular}

These findings are consistent with a change in synaptic properties of neurons within the LAvl after fear conditioning. However, based on previous reports identifying activated neurons histochemically, only a subset of neurons within the LAvl are expected to have altered properties (Wilson and Murphy, 2009; Trogrlic et al., 2011; Butler et al., 2015). To

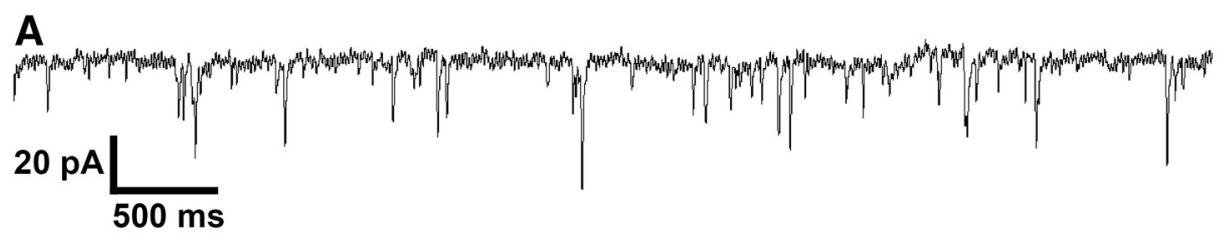

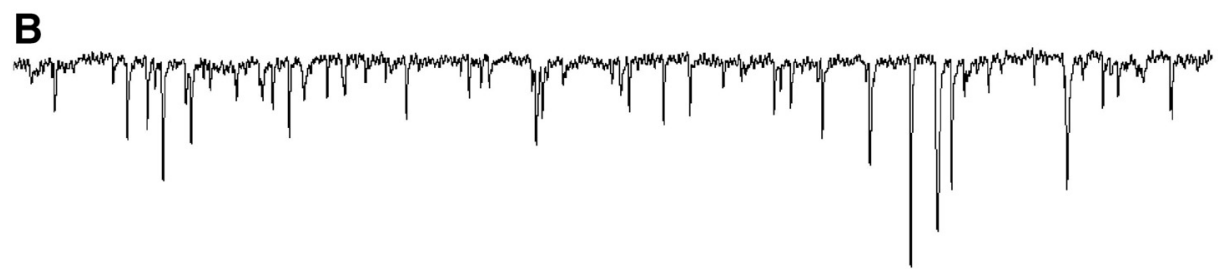

\section{Cumulative Frequency of sPSC Inter-Event Interval}

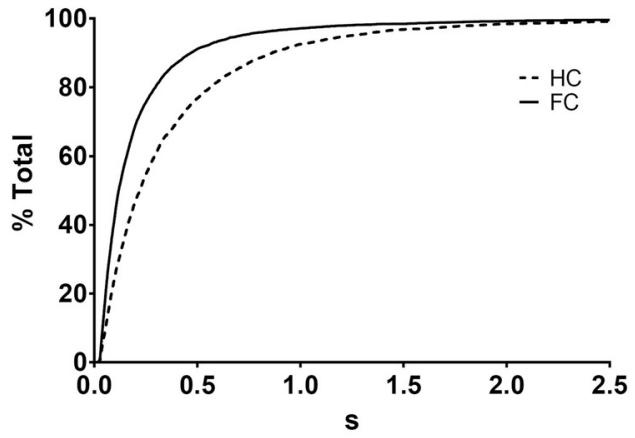

E

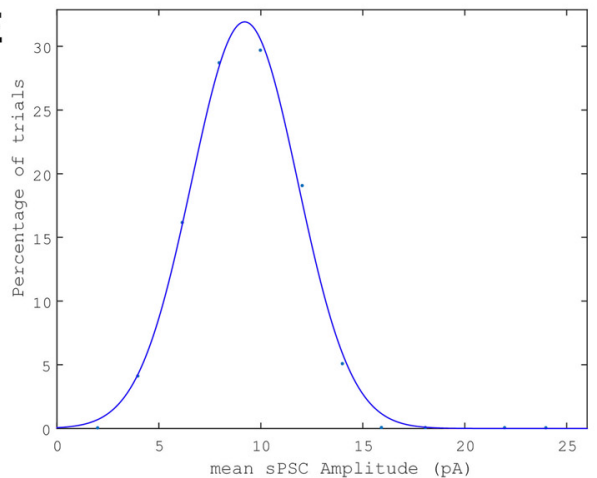

\section{Cumulative Frequency of sPSC Amplitude}
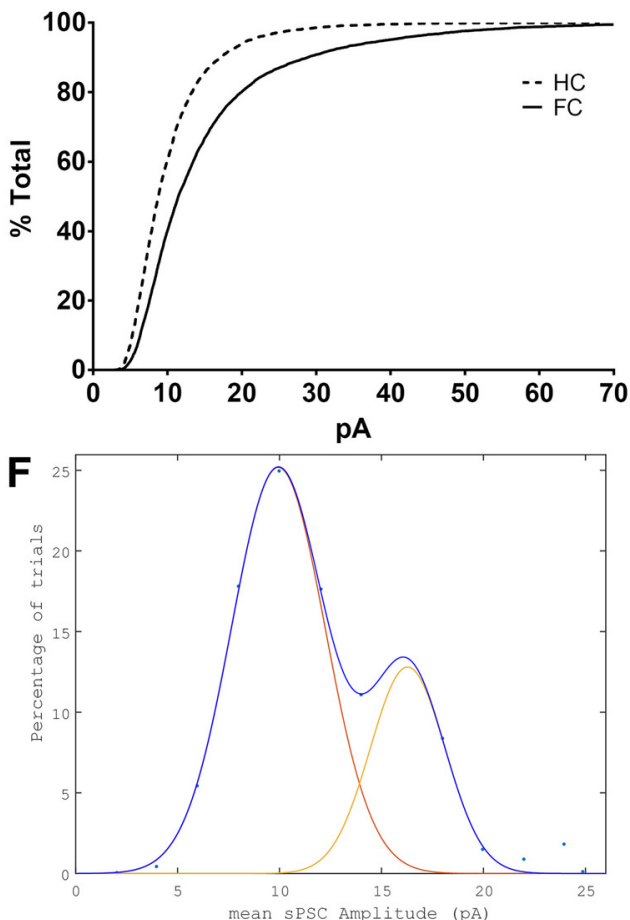

Figure 2. Learning induces increased synaptic activity in a subpopulation of LAvl neurons. Raw traces of sPSCs from (A) home cage mice $(\mathrm{HC})$ and $(\boldsymbol{B})$ fear-conditioned mice $(\mathrm{FC})$. $\boldsymbol{C}$, The cumulative frequency graph of the IEI of sPSCs shows a significant left shift in fear-conditioned mice compared to home cage controls (Kolmogorov-Smirnov test $p<0.0001$ ). $\boldsymbol{D}$, The cumulative frequency graph of the amplitude of sPSCs shows a significant right shift in fear-conditioned mice, compared to home cage controls (KolmogorovSmirnov test $p<0.0001, n=28 \mathrm{HC}$ and $n=33 \mathrm{FC}$ ). $\boldsymbol{E}$, A Gaussian fit to the frequency histogram of the sPSC amplitude of neurons from home cage controls shows a single peak. $\boldsymbol{F}$, A second peak is evident in fear-conditioned mice. 
explore this further, we applied a Gaussian peak-fitting algorithm to the average SPSC amplitude of each cell recorded from either fear-conditioned or home-caged mice (Fig. 2E,F). The algorithm identified a single Gaussian distribution peaking at $9.2 \mathrm{pA}$ for home-caged mice but identified two Gaussian peaks (at 9.9 and $16 \mathrm{pA}$ ) in conditioned mice. The Gaussian peak-fitting algorithm was also applied to SPSC frequency data. The algorithm identified three peaks (at 2.5, 5, and $10 \mathrm{~Hz}$ ), which were at similar frequencies in each condition (data not shown). However, the proportions of cells that fell within each peak differed between conditions. The Gaussian fit to the highest frequency accounted for $25 \%$ of cells in the fear learning mice but only $4 \%$ in home-caged mice. These empirical observations are consistent with the idea that only a subpopulation of neurons in LAvl exhibit altered properties following fear learning (Repa et al., 2001; Sehgal et al., 2014), and with previous findings that fear learning activates a specific subpopulation of neurons in LAvl (Wilson and Murphy, 2009; Trogrlic et al., 2011; Butler et al., 2015). We next used an approach that allowed the electrophysiological recording of neurons specifically activated by fear conditioning.

\section{Identification of $\boldsymbol{F T L}^{+}$learning-specific neurons in LAvl}

To test the electrophysiological properties of activated neurons, we developed a method to label and identify them in live brain slices based on the FTL mouse. The FTL mouse consists of a tau-LacZ transgene driven by the c-fos promoter, which results in expression of $\beta$-galactosidase throughout neurons in which $c$-fos has been expressed. First, we determined if the expected pattern of learning activated neurons in LAvl could be identified in the thick brain slices used for electrophysiology. For this, FTL mice were context fear-conditioned and then tested for contextassociated fear $3 \mathrm{~h}$ later. Mice trained in fear conditioning spent a significantly higher percentage of time freezing during this testing session than during the pre-shock period in training (Fig. $3 A$; pre-shock $M=28, S D=14$; Test $M=0.14$, $\left.S D=0.38 ; t_{(12)}=5.2, p=0.0002\right)$. The trained mice also spent a significantly lower percentage of time moving during testing when compared to the pre-shock training session (Fig. $3 B$; pre-shock $M=6.9, S D=4$; Test $M=25, S D=4$; $\left.t_{(12)}=8.2, p<0.0001 ;\right)$. Conditioned mice had therefore acquired a context-associated fear memory. Thick brain slices prepared for electrophysiological analysis were taken from these mice and stained for $\beta$-galactosidase. These slices showed a clear pattern of $F T L$ activation in a small subset of neurons along the border of the LAvl, with only a few $\mathrm{FTL}^{+}$neurons visualized in equivalent sections from immediate shock mice (Fig. 3C,D). The pattern of $\mathrm{FTL}^{+}$ neurons we observed in conditioned mice is consistent with the pattern of $F T L$ activity described in previous studies (Wilson and Murphy, 2009; Trogrlic et al., 2011; Butler et al., 2015).

We then developed a novel methodology using the fluorogenic $\beta$-galactosidase substrate $\mathrm{C}_{12} \mathrm{FDG}$ as a marker of $F T L$ expressing neurons in acute brain slices (Fig. $4 A$ ). $\mathrm{C}_{12} \mathrm{FDG}$ is a $\beta$-galactosidase substrate that is cell permeable (Zhang et al., 1991; Plovins et al., 1994), and in the presence of $\beta$-galactosidase, the galactopyra-
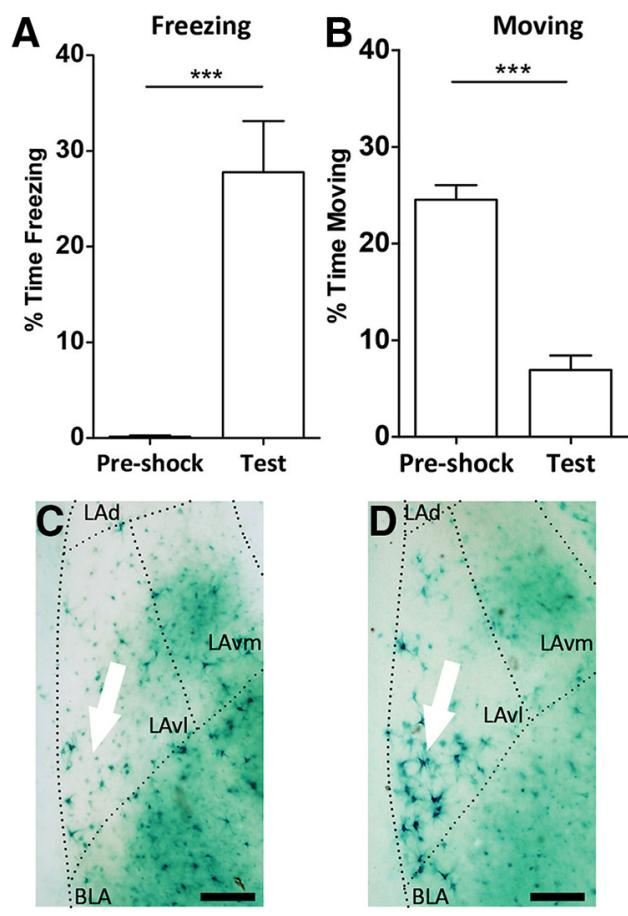

Figure 3. Restricted expression of $\mathrm{FTL}^{+}$neurons in thick brain slices following fear conditioning. Context fear-conditioned mice acquired a fear memory illustrated by increased $(\boldsymbol{A})$ freezing relative to pre-shock levels $(\boldsymbol{p}=0.0002)$ and $(\boldsymbol{B})$ decreased movement $(p<$ $0.0001, n=7$ ). $\boldsymbol{C}, \boldsymbol{D}$, Micrograph of the amygdala region of an $F T L$ mouse stained with $\mathrm{x}$-gal histochemistry following immediate shock training (non-learning control; $\boldsymbol{C}$ ) and following delayed shock training (fear-conditioned; $\boldsymbol{D}$ ), showing an increase in $\mathrm{FTL}^{+}$neurons specifically in the LAvl. Scale bars in $\boldsymbol{C}, \boldsymbol{D}: 150 \mu \mathrm{m}$. *** indicates statistically significant change.

nose moieties are cleaved to yield a fluorescent product (Rotman et al., 1963). FTL ${ }^{+}$neurons in the LAvl of contextfear-conditioned mice were identified based on their fluorescent signal. Post hoc analysis of biocytin-filled neurons confirmed their FTL identity: the biocytin signal overlapped with that of $\beta$-galactosidase for $\mathrm{FTL}^{+}$neurons while, if the neuron was $F T L^{-}$, only the biocytin signal was seen (Fig. 4B,C). These findings demonstrated that it was possible to identify $\mathrm{FTL}^{+}$neurons in acute brain slices using $\mathrm{C}_{12} \mathrm{FDG}$, which could then be targeted for wholecell patch clamp recordings. We observed no differences in the recorded passive properties of $\mathrm{FTL}^{+}$and $\mathrm{FTL}^{-}$ neurons as reported in Table 1.

\section{Increased spontaneous synaptic activity in learning- specific neurons}

To examine synaptic changes that may have occurred following context fear conditioning, we recorded SPSCs from the $\mathrm{FTL}^{+}$and $\mathrm{FTL}^{-}$neurons in the LAvl of the fear-conditioned mice at a holding potential of $-70 \mathrm{mV}$ (Fig. $4 D, E$ ). The cumulative frequency plot of the IEI for SPSCs showed a significant left-shift of the curve for $F T L^{+}$ neurons compared to $F^{-} L^{-}$neurons (Fig. 4F; Kolmogorov-Smirnov $\mathrm{D}=0.29, p<0.0001$, averaged data: $F T L^{-}$ $M=0.52 \mathrm{~s}, S D=0.57 ; \mathrm{FTL}^{+} M=0.25 \mathrm{~s}, S D=0.25$; $\left.t_{(562)}=10.7, p<0.0001\right)$. Furthermore, the cumulative 
A

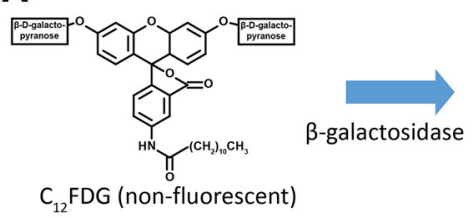

${ }_{12}$ FDG (non-fluorescent)

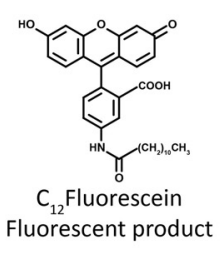

Fluorescent product

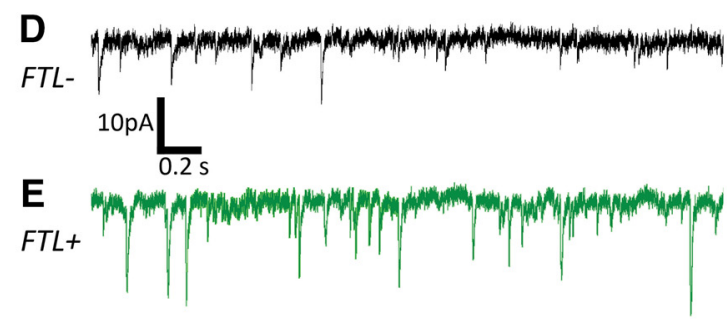

$\mathbf{F}$

sPSC Inter-Event Interval

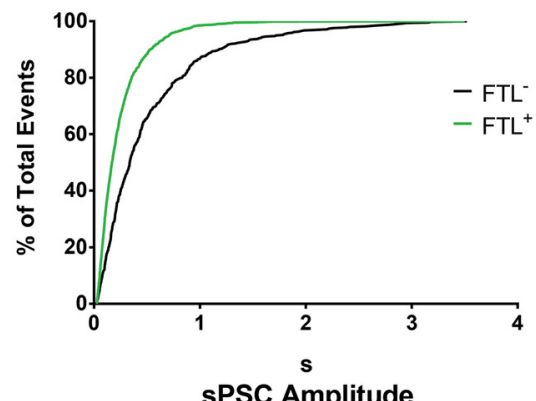

G

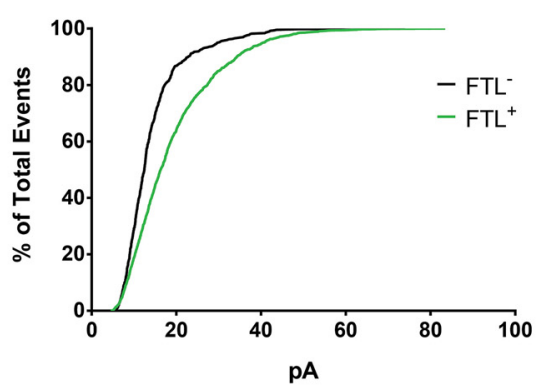

Figure 4. $\mathrm{FTL}^{+}$neurons in the LAvl show increases in SPSC frequency and amplitude. $\boldsymbol{A}, \mathrm{C}_{12} \mathrm{FDG}$ is converted to the fluorescent product $\mathrm{C}_{12}$-fluorescein by $\beta$-galactosidase, enabling the identification of $F T L^{+}$neurons in acute brain slices. $F T L^{+}(\boldsymbol{B})$ and $F T L^{-}(\boldsymbol{C})$ neurons identified post hoc by double labeling for $\beta$-galactosidase and biotin from intracellular recording. Representative voltageclamp traces from $(\boldsymbol{D}) \mathrm{FTL}^{-}$and $(\boldsymbol{E}) \mathrm{FTL}^{+}$neurons in the LAvl of context fear-conditioned mice. $\boldsymbol{F}$, Cumulative frequency histogram of the IEls of recorded sPSCs from $\mathrm{FTL}^{+}$and $\mathrm{FTL}^{-}$neurons (Kolmogorov-Smirnov test $p<0.0001$ ). G, Cumulative frequency histogram of the amplitudes of recorded sPSCs from $F_{T L}^{+}$and $F T L^{-}$neurons (Kolmogorov-Smirnov test $p<0.0001, n=6 F^{-}$and $n=7 \mathrm{FTL}^{+}$). Scale bars in $\boldsymbol{B}, \mathbf{C}: 25 \mu \mathrm{m}$.

frequency plot of the sPSC amplitude showed a significant right shift of the curve for $F T L^{+}$neurons compared to $F T L^{-}$neurons (Fig. 4G; Kolmogorov-Smirnov $D=0.27$, $p<0.0001, F T L^{-} M=14 \mathrm{pA}, S D=8 ; F T L^{+} M=19 \mathrm{pA}$, $\left.S D=11 ; t_{(1228)}=11.0, p<0.0001\right)$. Together, these observations illustrate an increase in both the frequency and amplitude of synaptic activity onto $\mathrm{FTL}^{+}$neurons when compared with neighboring $\mathrm{FTL}^{-}$neurons.

In a subset of these neurons we were able to record sPSC at a holding potential of $-50 \mathrm{mV}$, which is near the reversal potential of $\mathrm{Cl}^{-}$(Fig. 5A). The pattern of reduced sPSCs IEI (Fig. 5B; Kolmogorov-Smirnov $D=0.53, p<$ 0.0001; averaged data: $F T L^{-} M=1.8 \mathrm{~s}, S D=2 ; F T L^{+}$ $\left.M=0.43 \mathrm{~s}, S D=0.50 ; t_{(133)}=7.6, p<0.0001\right)$ and increased amplitude (Fig. $5 \mathrm{C}$; Kolmogorov-Smirnov $\mathrm{D}=$ 0.273, $p<0.0001$; averaged data: $F L^{-} M=14 \mathrm{pA}$, $\left.S D=8 ; F T L^{+} M=16 \mathrm{pA}, S D=7 ; t_{(164)}=3.0, p=0.0027\right)$ was still observed under these conditions, suggesting that the observed increase in synaptic activity was, at least in part, through excitatory transmission. Together, these findings indicate that the neurons in LAvl activated to express FTL by fear conditioning have undergone significant learning-induced synaptic plasticity.

\section{Firing properties of LAvl neurons after fear-induced learning}

Analysis of the firing properties of LAvl neurons in wild type experimental mice reveals a similar input/output relationship (Fig. 6A-C) and rheobase (home caged (HC) $M=60 \mathrm{pA}, S D=40 \mathrm{pA}$; fear conditioned (FC) $M=57 \mathrm{pA}$, $S D=18 \mathrm{pA} ; t_{(29)}=0.34$, ns) between conditioned and home cage control mice. Fear conditioning did induce significant changes in the shape of LAvl APs, as measured by the peak height, peak width, rise parameter, and decay parameter (Table 2).

Firing properties of $\mathrm{FTL}^{-}$and $\mathrm{FTL}^{+}$neurons recorded from fear-conditioned mice were similar with no differences in the input/output relationship (Fig. $6 D-F$ ) or rheobase $\left(F T L^{+} M=87 \mathrm{pA}, S D=51 \mathrm{pA} ; F T L^{-} M=104 \mathrm{pA}\right.$, $\left.S D=44 \mathrm{pA} ; t_{(10)}=0.59, \mathrm{~ns}\right)$. There was also no difference in the shape of APs produced by $\mathrm{FTL}^{+}$and $\mathrm{FTL}^{-}$neurons, as measured by the peak height, peak width, rise parameter, and decay parameter (Table 2). It should be noted, 
A

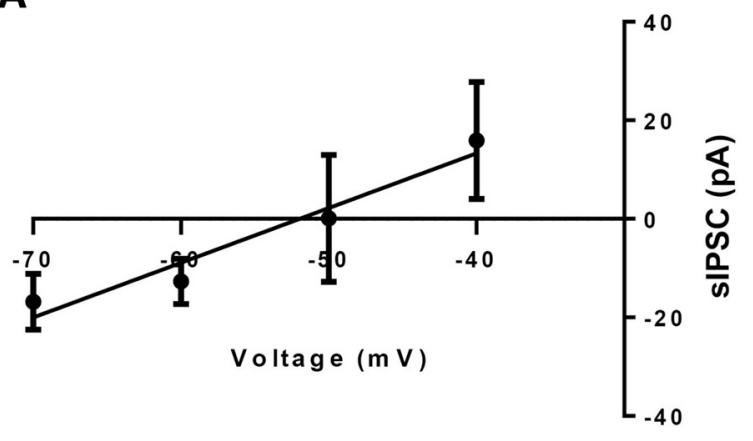

B $\quad$ SPSC Inter-Event Interval at $-50 \mathrm{mV}$

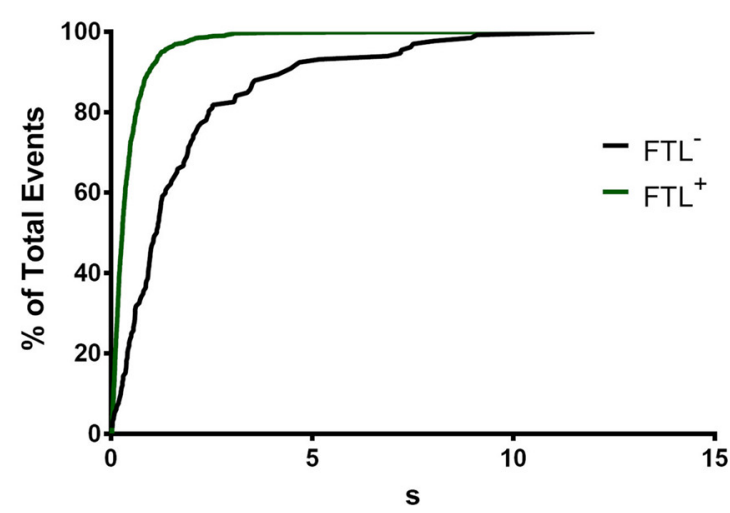

C sPSC Amplitude at $-50 \mathrm{mV}$

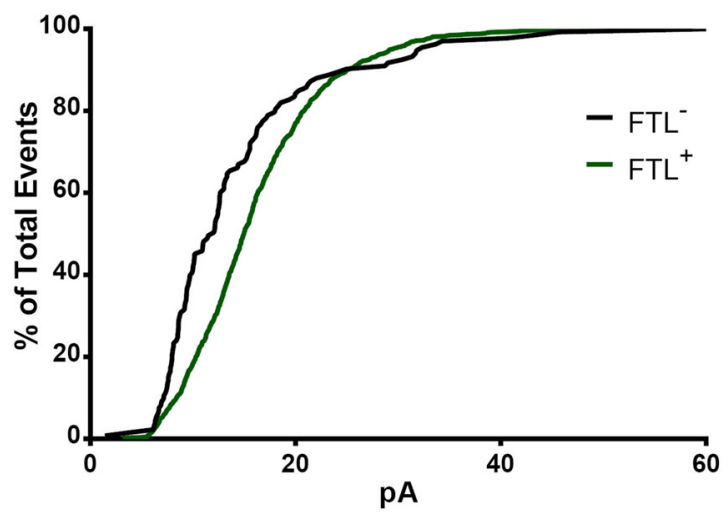

Figure 5. Increases in the spontaneous excitatory synaptic current event amplitude and frequency. A, Average spontaneous inhibitory PSC (sIPSC) amplitude at varying holding potentials in the presence of NBQX and APV from neurons in the mouse LA, showing a reversal potential of $\mathrm{Cl}^{-}$of approximately $-50 \mathrm{mV}(n=$ 7). $\boldsymbol{B}$, The cumulative frequency graph of the IEI of sPSCs from $\mathrm{FTL}^{+}$and $\mathrm{FTL}^{-}$neurons at $-50 \mathrm{mV}$ (Kolmogorov-Smirnov test $p<0.0001)$. $\boldsymbol{D}$, The cumulative frequency graph of the amplitude of sPSCs at $-50 \mathrm{mV} \mathrm{FTL}^{+}$and $\mathrm{FTL}^{-}$neurons (KolmogorovSmirnov test $p<0.0001, n=4 \mathrm{FTL}^{-}$and $\left.n=6 \mathrm{FTL}^{+}\right)$.

given the low number of recorded neurons, that small changes in AP properties may not have been detected.

\section{Discussion}

Previous studies identified a spatially discrete population of neurons within LAvl which was specifically acti- vated by fear conditioning (Wilson and Murphy, 2009; Trogrlic et al., 2011; Butler et al., 2015). These neurons are, therefore, specifically implicated in fear memory formation. To look for memory related electrophysiological changes within LAvl, we first recorded from neurons in wild-type mice following fear conditioning. These recordings revealed a subpopulation of neurons in LAvl that exhibited increases in SPSC frequency and amplitude compared with neurons from home-caged mice. to target the discrete population of neurons within LAvl which was specifically activated by fear conditioning, we then developed a method of identifying and recording from $F T L^{+}$ neurons in FTL brain slices labeled for $\beta$-galactosidase. Neurons that exhibited learning-specific $\beta$-galactosidase activation displayed increased SPSC frequency and amplitude compared to neighboring non-labeled neurons. Recordings of a subset of these labeled neurons at the reversal potential of $\mathrm{Cl}^{-}$suggest that, at least in part, the increases in amplitude and frequency of synaptic events are mediated through excitatory transmission. These findings provide evidence that increases in synaptic strength in a small, spatially discrete population of neurons in LA form part of the fear memory engram.

The fluorogenic $\beta$-galactosidase substrate $\mathrm{C}_{12} \mathrm{FDG}$ has been previously used primarily in flow cytometry applications, including for the analysis of mammalian cell types (Gu et al., 1993; Miao et al., 1993; Beattie et al., 1994). However, the use of $\mathrm{C}_{12}$ FDG to identify cells for electrophysiological analysis has not been previously reported. A number of other fluorogenic $\beta$-galactosidase substrates exist (Haugland and Johnson, 1993) however $\mathrm{C}_{12}$ FDG was chosen as it is nontoxic, well retained by cells, and able to passively enter mammalian cells in an aqueous environment (Zhang et al., 1991; Plovins et al., 1994). Our study highlights the use of $\mathrm{C}_{12} \mathrm{FDG}$ as a robust method of identifying labeled neurons expressing any construct that uses $\beta$-galactosidase expression as a marker.

Two recent studies investigated the synaptic properties of $\mathrm{Arc}^{+}$neurons in LA after fear conditioning (Nonaka et al., 2014; Gouty-Colomer et al., 2016), based on the premise that Arc expression is indicative of a neuron's involvement in fear learning and memory. Nonaka and colleagues report an increase in the frequency of synaptic currents on $\mathrm{Arc}^{+}$neurons compared to neighboring $\mathrm{Arc}^{-}$ neurons in conditioned mice (Nonaka et al., 2014). Furthermore, Gouty-Colomer and colleagues also demonstrate synaptic plasticity with increased evoked excitatory currents in $\mathrm{Arc}^{+}$neurons postlearning (Gouty-Colomer et al., 2016). These increases in synaptic event frequency and amplitude were comparable to those observed in the current study. However, it is worth noting that Arc expression in these studies may not have been indicative of a neuron's involvement in memory since there were substantial numbers of $\mathrm{Arc}^{+}$neurons in the non-learning controls, and fear learning stimulated only a small (GoutyColomer et al., 2016) or insignificant increase (Nonaka et al., 2014) in Arc expression. Thus, the synaptic changes observed in $\mathrm{Arc}^{+}$neurons may have been associated with either learning or non-learning stimuli, such as footshock. 

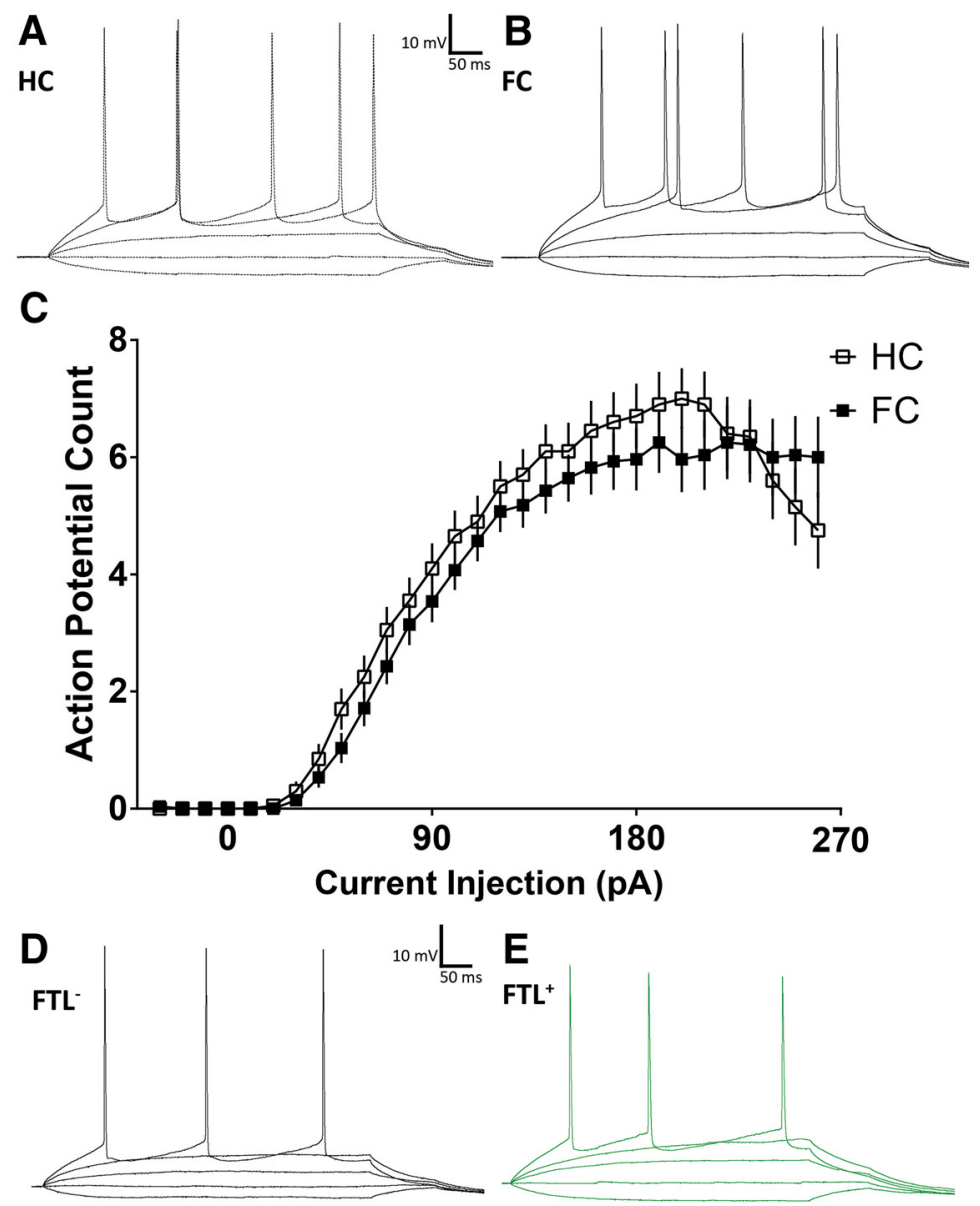

$\mathbf{F}$

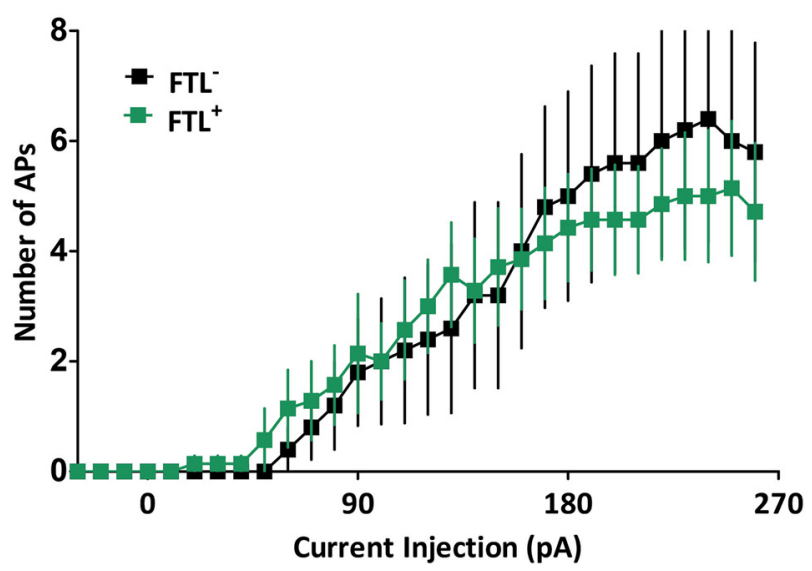

Figure 6. LAvl neurons show no differences in firing properties following fear conditioning. $\boldsymbol{A}$, B, Representative traces from current-clamped $(\boldsymbol{A})$ home cage $(\mathrm{HC})$ and $(\boldsymbol{B})$ fear-conditioned $(\mathrm{FC})$ neurons in the LAvl. $\boldsymbol{C}$, Mean AP count versus current injection for neurons from context fear-conditioned mice and from untrained home cage mice ( $n=28 \mathrm{HC}$ and $n=33 \mathrm{FC})$. Representative traces from current-clamped $(\boldsymbol{D}) \mathrm{FTL}^{-}$and $(\boldsymbol{E}) \mathrm{FTL}^{+}$neurons in the LAvl of context fear-conditioned mice. $\boldsymbol{F}$, Plot of the mean AP count versus current injection for $F T L^{+}$and $F T L^{-}$neurons from fear-conditioned mice $\left(n=6 \mathrm{FTL}^{-}\right.$and $\left.n=7 \mathrm{FTL}^{+}\right)$.

In contrast, the LAvl neurons from which we recorded express $F T L$ only following fear learning with an average 4-fold increase in $\mathrm{FTL}^{+}$neurons in trained mice compared to unpaired or shock controls (Wilson and Murphy 2009; Trogrlic et al., 2011; Butler et al., 2015). We can thus directly argue that the synaptic changes we observed occurred in neurons that were specifically involved in fear learning.

Our findings of synaptic plasticity can be incorporated into a model of fear learning and memory within the LA as follows. Both context and auditory fear learning induce c-fos in a small subset of LAvl neurons (Butler et al., 2015). 
Table 2. AP properties of LAvl neurons

\begin{tabular}{|c|c|c|c|c|c|c|c|c|}
\hline & \multicolumn{4}{|c|}{ Untargeted neurons } & \multicolumn{4}{|c|}{ Targeted neurons } \\
\hline & $\mathrm{HC}$ & $\mathrm{FC}$ & $t$ & $p$ & $F T L^{+}$ & $F T L^{-}$ & $t$ & $p$ \\
\hline AP height (mv) & $88 \pm 7$ & $83 \pm 9$ & 2.0 & 0.047 & $89 \pm 5$ & $85 \pm 14$ & 0.62 & 0.55 \\
\hline Rise time (10-90\% peak height, ms) & $0.6 \pm 0.1$ & $0.7 \pm 0.1$ & 3.6 & 0.0007 & $0.6 \pm 0.1$ & $0.6 \pm 0.2$ & 0.039 & 0.97 \\
\hline Decay time (100-50\% peak height, ms) & $1.5 \pm 0.2$ & $1.7 \pm 0.2$ & 2.3 & 0.028 & $1.5 \pm 0.3$ & $1.6 \pm 0.4$ & 0.33 & 0.75 \\
\hline
\end{tabular}

Given that the LA is crucial for the formation of the association between the conditioned and unconditioned stimuli (Fanselow and LeDoux, 1999; LeDoux, 2000; Blair et al., 2001; Maren, 2001, 2005), neurons involved in fear memory in the LA are possibly a site of convergence of these stimuli. Tracing studies from regions of the thalamus which deliver conditioned stimuli and unconditioned stimuli to the LA show extensive projections to LAvl (LeDoux, 2000). These findings are thus consistent with conditioned stimuli and unconditioned stimuli inputs converging on LAvl neurons, with associative firing of these two pathways resulting in the induction of synaptic plasticity during fear learning. In this model, these LAvl neurons project to downstream regions of the brain which control fear pathways and which are intrinsically activated during signaling from aversive unconditioned stimuli (Fanselow and LeDoux, 1999; LeDoux, 2000; Blair et al., 2001; Maren, 2001, 2005). We propose that the key synaptic changes on these neurons occur at the conditioned stimuli inputs which were activated during fear conditioning and would result in an altered response of these neurons to the conditioned stimuli. This altered response, such as increased frequency and/or amplitude of SPSC, would increase the probability of $\mathrm{AP}$ firing and consequently activate the downstream fear pathways in the absence of a unconditional stimulus. After fear learning, the animal would thus display a fear response when exposed to the conditioned stimuli alone. While key aspects of this model need to be examined and tested, it provides a reasonable explanation for how the changes we observed within a small population of neurons in LAvl may underlie part of fear learning and memory.

A number of recent studies have proposed an alternative model of fear memory, whereby neurons in the BLA are incorporated into the memory trace based on their excitability directly before the time of training (Han et al., 2007; Zhou et al., 2009; Gouty-Colomer et al., 2016; Rogerson et al., 2016). Viral-mediated overexpression of CREB in LA neurons has been shown to result in increased neuronal excitability, and transfected neurons were more likely to form part of the fear memory trace (Zhou et al., 2009). Furthermore, optogenetic inactivation of these CREB-overexpressing neurons in the BLA results in attenuation of an acquired fear memory (Rogerson et al., 2016). We find no evidence of changes in the AP input-output relationship of $F T L^{+}$and $F T L^{-}$neurons. This finding differs from that of Gouty-Colomer and colleagues, who demonstrated that $\mathrm{ArC}^{+}$neurons had increased AP input-output gain (Gouty-Colomer et al., 2016). The basis of this discrepancy is unclear although it could reflect the relatively small number of neurons re- corded. Additionally, EGTA in our internal solution may mask conditioning-associated changes in neuronal firing due to its effects on calcium-activated currents. We have also labeled neurons using a different marker (c-fos, cf. Arc), and only neurons within the LAvl were targeted, which is a more anatomically restricted region than the wider BLA. Interestingly, we do see subtle changes in AP morphology at a population level in the LAvl of fearconditioned mice. This was not observed in our targeted approach with no difference in AP morphology observed between $\mathrm{FTL}^{+}$and $\mathrm{FTL}^{-}$neurons. The physiologic relevance of this is unclear and warrants future investigation.

In summary, we show that synaptic changes occur specifically on neurons activated by context fear conditioning in the LAvl, with no differences in intrinsic neuronal excitability being detected. These findings suggest a model of fear learning whereby learning-induced synapse modification occurs on neurons within an anatomically restricted region of the $L A$.

\section{References}

Beattie GM, Levine F, Mally MI, Otonkoski T, O’Brien JS, Salomon DR, Hayek A (1994) Acid beta-galactosidase: a developmentally regulated marker of endocrine cell precursors in the human fetal pancreas. J Clin Endocrinol Metab 78:1232-1240. CrossRef

Bergstrom HC, McDonald CG, Dey S, Tang H, Selwyn RG, Johnson LR (2013) The structure of Pavlovian fear conditioning in the amygdala. Brain Struct Funct 218:1569-1589. CrossRef Medline

Besnard A, Laroche S, Caboche J (2014) Comparative dynamics of MAPK/ERK signalling components and immediate early genes in the hippocampus and amygdala following contextual fear conditioning and retrieval. Brain Struct Funct 219:415-430. CrossRef Medline

Blair HT, Schafe GE, Bauer EP, Rodrigues SM, LeDoux JE (2001) Synaptic plasticity in the lateral amygdala: a cellular hypothesis of fear conditioning. Lear Mem 8:229-242. CrossRef

Butler CW, Wilson YM, Gunnersen JM, Murphy M (2015) Tracking the fear memory engram: discrete populations of neurons within amygdala, hypothalamus, and lateral septum are specifically activated by auditory fear conditioning. Lear Mem 22:370-384. CrossRef

Dragunow M (1996) A role for immediate-early transcription factors in learning and memory. Behav Genet 26:293-299. Medline

Fanselow MS, LeDoux JE (1999) Why we think plasticity underlying Pavlovian fear conditioning occurs in the basolateral amygdala. Neuron 23:229-232. Medline

Fanselow MS, Poulos AM (2005) The neuroscience of mammalian associative learning. Annu Rev Psychol 56:207-234. CrossRef Medline

Gouty-Colomer LA, Hosseini B, Marcelo IM, Schreiber J, Slump DE, Yamaguchi S, Houweling AR, Jaarsma D, Elgersma Y, Kushner SA (2016) Arc expression identifies the lateral amygdala fear memory trace. Mol Psychiatry 21:1153. CrossRef Medline 
Gu MB, Todd P, Kompala DS (1993) Foreign gene expression (betagalactosidase) during the cell cycle phases in recombinant $\mathrm{CHO}$ cells. Biotechnol Bioeng 42:1113-1123. CrossRef Medline

Han JH, Kushner SA, Yiu AP, Cole CJ, Matynia A, Brown RA, Neve RL, Guzowski JF, Silva AJ, Josselyn SA (2007) Neuronal competition and selection during memory formation. Science 316:457460. CrossRef

Han JH, Kushner SA, Yiu AP, Hsiang HL, Buch T, Waisman A, Bontempi B, Neve RL, Frankland PW, Josselyn SA (2009) Selective erasure of a fear memory. Science 323:1492-1496. CrossRef Medline

Haugland RP, Johnson ID (1993) Detecting enzymes in living cells using fluorogenic substrates. J Fluoresc 3:119-127. CrossRef Medline

Hebb DO (1949) The organisation of behaviour. New York: Wiley.

Johansen JP, Cain CK, Ostroff LE, LeDoux JE (2011) Molecular mechanisms of fear learning and memory. Cell 147:509-524. CrossRef Medline

Josselyn SA, Köhler S, Frankland PW (2015) Finding the engram. Nat Rev Neurosci 16:521-534. CrossRef Medline

Kim JJ, Jung MW (2006) Neural circuits and mechanisms involved in Pavlovian fear conditioning: a critical review. Neurosci Biobehav Rev 30:188-202. CrossRef Medline

Knapska E, Radwanska K, Werka T, Kaczmarek L (2007) Functional internal complexity of amygdala: focus on gene activity mapping after behavioral training and drugs of abuse. Physiol Rev 87:11131173. CrossRef Medline

LeDoux J (2007) The amygdala. Curr Biol 17:R868- R874. CrossRef Medline

LeDoux JE (2000) Emotion circuits in the brain. Annu Rev Neurosci 23:155-184. CrossRef Medline

Maren S (2001) Neurobiology of Pavlovian fear conditioning. Annu Rev Neurosci 24:897-931. CrossRef Medline

Maren S (2005) Synaptic mechanisms of associative memory in the amygdala. Neuron 47:783-786. CrossRef Medline

Miao F, Todd P, Kompala DS (1993) A single-cell assay of betagalactosidase in recombinant Escherichia coli using flow cytometry. Biotechnol Bioeng 42:708-715. CrossRef Medline

Murphy M, Greferath U, Wilson YM (2007) A method for detecting functional activity related expression in gross brain regions, specific brain nuclei and individual neuronal cell bodies and their projections. Biol Proced Online 9:1-8. CrossRef Medline

Nonaka A, Toyoda T, Miura Y, Hitora-Imamura N, Naka M, Eguchi M, Yamaguchi S, Ikegaya Y, Matsuki N, Nomura H (2014) Synaptic plasticity associated with a memory engram in the basolateral amygdala. J Neurosci 34:9305-9309. CrossRef Medline

Pape HC, Stork O (2003) Genes and mechanisms in the amygdala involved in the formation of fear memory. Ann NY Acad Sci 985: 92-105. Medline
Plovins A, Alvarez AM, Ibañez M, Molina M, Nombela C (1994) Use of fluorescein-di-beta-D-galactopyranoside (FDG) and C12-FDG as substrates for beta-galactosidase detection by flow cytometry in animal, bacterial, and yeast cells. Appl Environ Microbiol 60:46384641. Medline

Repa JC, Muller J, Apergis J, Desrochers TM, Zhou Y, LeDoux JE (2001) Two different lateral amygdala cell populations contribute to the initiation and storage of memory. Nat Neurosci 4:724-731. CrossRef Medline

Rogerson T, Jayaprakash B, Cai DJ, Sano Y, Lee YS, Zhou Y, Bekal P, Deisseroth K, Silva AJ (2016) Molecular and cellular mechanisms for trapping and activating emotional memories. PLoS One 11:e0161655. CrossRef Medline

(Rotman B, Zderic JA, Edelstein M (1963) Fluorogenic substrates for beta-D-galactosidases and phosphatases derived from flurescein (3,6-dihydroxyfluoran) and its monomethylether. Proc Natl Acad Sci USA 50:1-6. Medline

Schafe GE, Atkins CM, Swank MW, Bauer EP, Sweatt JD, LeDoux JE (2000) Activation of ERK/MAP kinase in the amygdala is required for memory consolidation of pavlovian fear conditioning. J Neurosci 20:8177-8187. Medline

Sehgal M, Ehlers VL, Moyer JR Jr (2014) Learning enhances intrinsic excitability in a subset of lateral amygdala neurons. Lear Mem 21:161-170. CrossRef

Sosulina L, Meis S, Seifert G, Steinhäuser C, Pape HC (2006) Classification of projection neurons and interneurons in the rat lateral amygdala based upon cluster analysis. Mol Cell Neurosci 33:5767. CrossRef Medline

Sweatt JD (2016) Neural plasticity and behavior - sixty years of conceptual advances. J Neurochem 139:179-199. CrossRef Medline

Thompson RF (2005) In search of memory traces. Annu Rev Psychol 56:1-23. CrossRef Medline

Trogrlic L, Wilson YM, Newman AG, Murphy M (2011) Context fear learning specifically activates distinct populations of neurons in amygdala and hypothalamus. Lear Mem 18:678-687. CrossRef

Wilson YM, Murphy M (2009) A discrete population of neurons in the lateral amygdala is specifically activated by contextual fear conditioning. Lear Mem 16:357-361. CrossRef

Zhang YZ, Naleway JJ, Larison KD, Huang ZJ, Haugland RP (1991) Detecting lacZ gene expression in living cells with new lipophilic, fluorogenic beta-galactosidase substrates. FASEB J 5:31083113. Medline

Zhou Y, Won J, Karlsson MG, Zhou M, Rogerson T, Balaji J, Neve R, Poirazi P, Silva AJ (2009) CREB regulates excitability and the allocation of memory to subsets of neurons in the amygdala. Nat Neurosci 12:1438-1443. CrossRef Medline 